\title{
EDUCAÇÃO, ALFABETIZAÇÃO E LETRAMENTO: A REVISTA CRIANÇA E SUA SEÇÃO CALEIDOSCÓPIO
}

\author{
Education, literacy and lettering: the Child Magazine and its Kaleidoscope Section
}

\author{
Educación, alfabetización y letramiento: la Revista Criança y su Sección \\ Caleidoscopio
}

\author{
Maria Angélica Olivo Francisco Lucas* \\ Cicília Rodrigues Monteiro**
}

\begin{abstract}
Resumo
O objetivo deste artigo foi mapear as orientações teórico-metodológicas mais frequentes acerca dos processos de alfabetização e letramento presentes na seção "Caleidoscópio" do impresso pedagógico Revista Criança, periódico destinado, principalmente, aos professores de educação infantil, mas acessível também aos docentes dos anos iniciais do ensino fundamental. Por meio da análise das fontes, verifica-se porque a temática alfabetização e letramento esta praticamente ausente das orientações destinadas aos professores das crianças pequenas. O estudo pode contribuir para comunidade escolar, por tratar de uma temática importante diante do quadro educacional brasileiro, representado, entre outros, por dados resultantes da Provinha Brasil e pelo Índice de Desenvolvimento Educacional (IDEB).
\end{abstract}

PALAVRAS-CHAVE: Educação. Alfabetização. Letramento. Revista Criança.

\begin{abstract}
The aim of this paper is to show some results obtained from the mapping on the theoretical and methodological orientations of the most frequent processes on alphabetization and literacy present in the pedagogical section "Kaleidoscope" on the printed version of the Child Magazine. This journal is designed mainly for teachers of early childhood education, yet it is also available to teachers from the early years of elementary school. It is found on the website of MEC. To support this research it was used the main theoretical framework studies by Magda Soares about the processes of literacy and alphabetization. The author understands that the process of learning alphabetization as necessary for the acts of reading and writing and literacy is the state or condition of the subject that incorporates social practices of reading and writing skills. The relevance of this study lies on the contribution that it may mean for the initial and continuing teacher formation, since it is an important issue on the Brazilian educational context, represented, among others, by the results of Exam Brazil and the Index of Basic Education Development (IDEB). It is a bibliographical research with descriptive and interpretive character, whose analysis of the sources was performed in several stages: selection of the Child Magazine issues to be studied (number 38-46); readings and record keeping of the articles present in these issues; session definition and items to be studied and analyzed. It has been found that the thematic alphabetization and literacy, dealt with explicitly and directly, is virtually absent from

\footnotetext{
* Doutora em Educação pela Faculdade de Educação da Universidade de São Paulo (USP). Professora do Programa de Pós-graduação em Educação da Universidade Estadual de Maringá (UEM). Endereço: Rua Marcelino Champagnat, 502, Zona 02 - Maringá/PR. Email: mangelicaofl@ibest.com.br.

* Pedagoga pela Universidade Estadual de Maringá (UEM). Aluna/Bolsista CAPES do Programa de PósGraduação (Mestrado 2013/2015) da Universidade Estadual de Maringá (UEM). Endereço: Rua São João, 8, apartamento 64, Zona 07 - Maringá/PR. Email: cicilia_rm@ hotmail.com.
} 
the guidelines conveyed by the journal in study. Nevertheless, there are other theoretical and methodological orientations - the role of literature in the learning and development process; the relation between the care and education; evaluation; transition from primary education up to nine years teaching and curriculum - present in the journal interfere indirectly in the subject studied.

KEYWORDS: Education. Alphabetization. Literacy. Child Magazine.

\section{Resumen}

El objetivo de este artículo fue mapear las orientaciones teórico-metodológicas más frecuentes sobre los procesos de alfabetización y letramiento presentes en la sección "Caleidoscopio" del impreso pedagógico Revista Criança, periódico destinado, principalmente, a los profesores de la educación infantil, pero accesible también a los de los años iniciales de la enseñanza fundamental. Por medio del análisis de las fuentes, también se verifica porqué la temática alfabetización y letramiento está prácticamente ausente de las orientaciones destinadas a los profesores del nivel de enseñanza en discusión. La relevancia de este estudio se encuentra en la contribución que éste puede significar para los alumnos del Curso de Pedagogía, por ser necesario en la formación inicial de profesores, y para la educación de forma general, una vez que se trata de una temática importante delante del cuadro educacional brasileño, representado, entre otros, por los resultados de la Provinha Brasil y por el Índice de Desarrollo Educacional.

PALABRAS CLAVE: Educación. Alfabetización. Letramiento. Revista Criança.

\section{INTRODUÇÃO}

Este artigo tem por objetivo apontar as principais orientações teóricometodológicas voltadas para os processos de letramento e alfabetização em edições da Revista Criança, publicada pelo Ministério da Educação e Cultura (MEC). Por meio dos resultados do estudo ora apresentado, possa-se colaborar tanto com a formação continuada, como a formação inicial de professores para atuarem na educação infantil e nos anos iniciais do ensino fundamental, contribuindo para elevação da qualidade da Educação Básica, diante do precário quadro educacional brasileiro, revelado, entre outros, pelos resultados da Provinha Brasil e pelo Índice de Desenvolvimento Educacional (IDEB).

A ampliação do ensino fundamental para nove anos de duração reacendeu a conturbada relação entre a aprendizagem da linguagem escrita e a educação infantil, aparentemente resolvida no campo teórico, uma vez que professores deste nível de ensino e dos anos iniciais do ensino fundamental, carecem de orientações teóricometodológicas acerca do planejamento e aplicação de práticas pedagógicas que envolvam a alfabetização na perspectiva do letramento. Essas considerações baseiam-se em experiências proporcionadas por práticas pedagógicas vivenciadas, discutidas, planejadas e implementadas pelas autores deste artigo, em instituições de ensino participantes do Programa Institucional de Bolsa de Iniciação a Docência, durantes os anos letivos de 2010 a 2012 da Universidade Estadual de Maringá. A aproximação com tais instituições e o olhar atento às dificuldades apresentadas no planejamento e no encaminhamento da prática pedagógica dos professores revelou a necessidade de pesquisar em diferentes materiais de apoio, orientações teórico-metodológicas que atendessem a necessidade de apropriação do código escrito e suas dimensões sociais. 
Entre estes materiais de apoio encontra-se a Revista Criança ${ }^{1}$, periódico de ampla e gratuita circulação, com tiragem de cerca de 200.000 exemplares por edição e que tem como público alvo os professores de educação infantil, podendo atingir também professores dos anos iniciais do ensino fundamental. $\mathrm{O}$ impresso conta com a participação de grandes pesquisadores e tem o objetivo, segundo Oliveira (2011), subsidiar a formação docente continuada, estimulando a reflexão e a divulgação de estudos e experiências na área da educação infantil.Trata-se, portanto, de uma estratégia simples de atingir e atualizar os professores, criada no ano de 1982, em um contexto de abertura e política marcado pela busca de democratização da sociedade brasileira e, como consequência, de reorganização das instituições, inclusive educativas.

Haja vista sua importância no cenário político, a Revista Criança constitui-se como fonte acessível de consulta para os professores. Para consolidar a análise escolhese estudar somente os exemplares que estão disponíveis na internet, que vão da edição de número 38 até 46. A justificativa para o referido recorte está no fato de que tal periódico não é comercial, seus exemplares, a partir da edição indicada, são veiculados pelo portal do Ministério da Educação (MEC) e estão à disposição de todos que quiserem consultá-la e aprimorar seus conhecimentos.

Para fundamentar as análises realizadas, foi utilizado como referencial teórico, os estudos realizados por Soares $(2001,2010)$ sobre a apropriação da linguagem escrita. Para Soares (2010), a discussão acerca da eficiência dos métodos de alfabetização iniciada nos anos 1950 - quando um terço dos estudos e pesquisas estava voltado à temática que trouxe como consequência a associação de equívocos e falsas inferências decorrentes do processo de divulgação da perspectiva construtivista de alfabetização e de propostas pedagógicas fundadas neste referencial teórico, obtém-se o que Soares (2010) caracteriza como a perda da especificidade da alfabetização.

A problemática, iniciada em meados da década de 1980, se estende até os dias atuais, diante da necessidade, apontada por Soares (2010), de recuperar a especificidade da alfabetização, reconhecendo a relação de indissociabilidade e interdependência entre este processo e os usos sociais da leitura e da escrita, o que torna relevante a produção de materiais de apoio ao professor, como é o caso da Revista Criança, que apesar de conter matérias com pontos de vistas divergentes, veicula importantes elementos para a compreensão do objeto de estudo - letramento e alfabetização.

\section{Revista Criança}

Como referencial teórico aponta-se as reflexões realizadas por Soares (2001, 2010) acerca da relação entre os processos de letramento e alfabetização - temática importante para formação inicial e continuada de professores da educação infantil e nos iniciais do ensino fundamental. Para Soares (2001), alfabetização significa aprendizagem da técnica e domínio dos códigos necessários à leitura e à escrita, das relações fonema/grafema e do uso dos instrumentos com os quais se escreve. Em linhas gerais significa aprender a usar o lápis e o papel, a codificar e decodificar. Letramento é definido pela autora, como aprendizagem dos usos e funções da leitura e da escrita em

\footnotetext{
${ }^{1}$ A Revista Criança foi a primeira publicação nacional voltada para a educação infantil. Está em circulação há 30 anos, mas não possui periodicidade regular.
} 
práticas sociais variadas, como escrever uma carta, um bilhete ou compreender a mensagem de um outdoor na rua. Alfabetizar e letrar, são processos indissociáveis e interdependentes, porém, específicos.

Atualmente, é comum a utilização por professores de diferentes níveis de ensino e pesquisadores da área educacional dos termos alfabetização e letramento. Entretanto, $\mathrm{s}$ Soares (2010) explica que até o final da década de 1970, no Brasil, ninguém mencionava as habilidades de leitura e de seus usos sociais, apesar do conceito existir nos Estados Unidos e na Inglaterra desde o final do século XIX, - denominado de literacy. Naquele período, a preocupação com a alfabetização centrava-se em torno da realização de cópias e da busca pelo traçado perfeito da letra, ou seja, priorizava-se o processo de codificação e decodificação. Foi somente na década de 1980 que ocorreu a criação do termo letramento, em outros países, curiosamente, em sociedades distanciadas geográfica e culturalmente: illettrisme na França, literacia em Portugal e letramento no Brasil.

A disseminação da temática fez com que se tornasse foco de discussões em artigos e livros publicados, levando ao desenvolvimento de programas avaliativos do nível de competências de leitura e de escrita da população. Soares (2010) afirma que os resultados dessas avaliações foram diferentes em países desenvolvidos e em desenvolvimento, como o Brasil. No primeiro caso a população, embora alfabetizada, não conseguia utilizar a linguagem escrita para exercer uma participação efetiva em práticas sociais e profissionais. No segundo caso, houve o reconhecimento da importância e necessidade de desenvolver habilidades de leitura e escrita, compreendendo que seu uso competente tem origem na aprendizagem inicial. A problemática estava no fato de que as crianças nem aprender a ler e escrever, nem a usar o código escrito, situação que gerava, segundo Soares (2010), altos índices de reprovação e repetência na etapa inicial do então primeiro grau.

A disseminação da teoria construtivista, na década de 1980, possibilitou a compreensão de que, para aprender, a criança precisa de uma relação significativa com o objeto de estudo. Contudo, um dos problemas é que dessa teoria derivaram falsas inferências e equívocos, fazendo com que a alfabetização perdesse sua especificidade. Se antes tínhamos métodos, mas, não tínhamos teoria, hoje temos teoria, mas, não temos métodos, afirma Soares (2010). Para autora professores passaram a ter "uma bela teoria construtivista", mas ficaram sem metodologia para ensinar a ler e escrever.

Como resultado temos crianças que não são, nem alfabetizadas, nem letradas. Não basta que a criança conviva com o material escrito, é preciso orientá-la, de forma intencional e organizada, para que ocorra a apropriação do sistema de escrita. Isso não significa que devemos voltar aos tradicionais métodos de alfabetização pautados no uso de cartilhas, mas que devemos buscar o equilíbrio entre os processos de letramento e alfabetização ao planejar e encaminhar a prática pedagógica (SOARES, 2010). Daí a necessidade de buscar orientações de cunho de teórico-metodológico, em fontes diversas, visando o encaminhamento da prática pedagógica.

Trata-se de uma pesquisa bibliográfica de caráter descritivo e interpretativo. Este tipo de procedimento, segundo Rocha e Bernardo (2011), é destinado, entre outros, a tratar de temas de ordem social, como por exemplo, os fenômenos educacionais. Assim, a descrição dos conteúdos presentes nas matérias veiculadas na sessão Caleidoscópio que compõem a Revista Criança permitiu a elaboração e o mapeamento das mais 
frequentes orientações teórico-metodológicas para práticas pedagógicas e a verificação da ausência de orientações explícitas acerca dos processos de letramento e alfabetização presentes no referido periódico.

Primeiramente procedeu-se a seleção das edições da Revista Criança analisadas, sendo elas as de número $38^{2}$ a 46 . Em seguida, foram selecionados dentre os artigos analisados, aqueles que continham orientações teórico-metodológicas acerca dos processos de alfabetização e letramento, as quais foram classificadas e organizadas em tabelas, de acordo com suas especificidades de cada temáticas. A escolha de seçãoCaleidoscópio deve-se ao fato de que a cada edição, três pontos de vista distintos ou complementares sobre um mesmo tema, são apresentados, como se se pode observar no Quadro 1:

Quadro I: Seção Caleidoscópio da Revista Criança.

\begin{tabular}{|c|c|c|c|}
\hline Revista & Título da matéria & Autor & Temática \\
\hline \multirow{3}{*}{38} & $\begin{array}{c}\text { O papel dos contos de fadas na construção } \\
\text { do imaginário infantil }\end{array}$ & $\begin{array}{l}\text { Isabel Maria de Carvalho } \\
\text { Vieira }\end{array}$ & \multirow{3}{*}{$\begin{array}{l}\text { Relação entre os contos } \\
\text { de fadas e o } \\
\text { desenvolvimento infantil }\end{array}$} \\
\hline & O conto de fadas & Nelly Novaes Coelho & \\
\hline & $\begin{array}{l}\text { Conversando e contando histórias, } \\
\text { recriando lugares }\end{array}$ & $\begin{array}{c}\text { Aures da Cunha } \\
\text { Marandola e Eduardo } \\
\text { Marandola Jr }\end{array}$ & \\
\hline \multirow{3}{*}{39} & $\begin{array}{c}\text { Integração de creches e pré-escolas e } \\
\text { habilitação de professores: qualidade na } \\
\text { educação infantil }\end{array}$ & JeaneteBeauchamp & \multirow{3}{*}{$\begin{array}{c}\text { Cuidar e educar como } \\
\text { aspectos indissociáveis na } \\
\text { educação de crianças de } 0 \\
\text { a } 6 \text { anos }\end{array}$} \\
\hline & $\begin{array}{l}\text { Criança e educação: uma trajetória } \\
\text { cultural e institucional }\end{array}$ & Fátima Camargo & \\
\hline & Pare! Respeite-me, também sou cidadão! & $\begin{array}{l}\text { Adenice do Socorro } \\
\text { Corrêa de Amorim, } \\
\text { Mônica Nascimento de } \\
\text { Brito, Sirlene do Socorro } \\
\text { Cunha Barros }\end{array}$ & \\
\hline \multirow{3}{*}{40} & $\begin{array}{l}\text { As instituições de educação infantil são } \\
\text { responsabilidade dos sistemas de ensino }\end{array}$ & Karina Rizek Lopes & \multirow{3}{*}{$\begin{array}{l}\text { A integração das } \\
\text { instituições de educação } \\
\text { infantil sob os pontos de } \\
\text { vista de um representante } \\
\text { do Ministério da } \\
\text { Educação, do Ministério } \\
\text { do Desenvolvimento } \\
\text { Social e de um município }\end{array}$} \\
\hline & $\begin{array}{l}\text { Pactuação de responsabilidades em prol } \\
\text { da inclusão social de crianças }\end{array}$ & Aidê Cançado Almeida & \\
\hline & $\begin{array}{l}\text { A integração de educação infantil e os } \\
\text { sistemas de ensino }\end{array}$ & $\begin{array}{l}\text { Ana Rosa de Andrade } \\
\text { Parente }\end{array}$ & \\
\hline \multirow{3}{*}{41} & $\begin{array}{l}\text { Avaliação sempre envolve uma } \\
\text { concepção de mundo }\end{array}$ & $\begin{array}{l}\text { Claudia de Oliveira } \\
\text { Fernandes }\end{array}$ & \multirow{3}{*}{$\begin{array}{l}\text { O processo de avaliação } \\
\text { na educação infantil }\end{array}$} \\
\hline & $\begin{array}{l}\text { Elaboração e organização de instrumentos } \\
\text { de acompanhamento e avaliação de } \\
\text { aprendizagem e desenvolvimento das } \\
\text { crianças }\end{array}$ & Adrianne Ogêda Guedes & \\
\hline & $\begin{array}{l}\text { O Portfólio como novo instrumento de } \\
\text { avaliação }\end{array}$ & Rosana Aragão & \\
\hline \multirow{3}{*}{42} & Desafios de um novo tempo & $\begin{array}{l}\text { Karina Rizek Lopes e } \\
\text { Roseana Pereira Mendes }\end{array}$ & \multirow{3}{*}{$\begin{array}{l}\text { Ampliação do ensino } \\
\text { fundamental para } 9 \text { anos }\end{array}$} \\
\hline & $\begin{array}{l}\text { A Criança de } 6 \text { anos no Ensino } \\
\text { Obrigatório: um Avanço Social }\end{array}$ & $\begin{array}{l}\text { Sandara Denise Pagel e } \\
\text { Aricélia Ribeiro do } \\
\text { Nascimento }\end{array}$ & \\
\hline & $\begin{array}{l}\text { A Criança de } 6 \text { anos no Ensino } \\
\text { Fundamental }\end{array}$ & Elvira Souza Lima & \\
\hline
\end{tabular}

${ }^{2}$ A edição 38 marcou a volta da Revista Criança que estava sem ser produzida desde novembro de 2005.

Educação e Fronteiras On-Line, Dourados/MS, v.9, n.26 p.154-165, maio/ago. 2019. 


\begin{tabular}{|c|c|c|c|}
\hline \multirow{3}{*}{43} & $\begin{array}{l}\text { Bases curriculares para Educação } \\
\text { Infantil? Ou isto ou aquilo }\end{array}$ & $\begin{array}{l}\text { Ângela Scalabrin Coutinho } \\
\text { e Eloisa Acires Candal } \\
\text { Rocha }\end{array}$ & \multirow{3}{*}{$\begin{array}{l}\text { O currículo e suas } \\
\text { múltiplas linguagens em } \\
\text { uma perspectiva cultural, } \\
\text { na pedagogia da infância }\end{array}$} \\
\hline & Os conteúdos em educação infantil & $\begin{array}{l}\text { Gabriel de Andrade } \\
\text { Junqueira Filho }\end{array}$ & \\
\hline & $\begin{array}{l}\text { Currículo e práticas pedagógicas na } \\
\text { educação infantil }\end{array}$ & $\begin{array}{l}\text { Anelise Monteiro do } \\
\text { Nascimento }\end{array}$ & \\
\hline
\end{tabular}

Por fim, procedeu-se a análise dos dados e como resultado desta pesquisa verificou-se a ocorrência de diferentes temáticas afetas à educação das crianças pequenas, desde a relação entre o cuidar e o educar até as políticas públicas dirigidas a este nível de ensino. Porém, foram constadas poucas orientações teórico-metodológicas afetas ao letramento e a alfabetização. Nesse sentido, optamos por apontarmos aquelas que se relacionam com tais processos, mas que são decisivas quando pensamos a respeito da escolarização inicial, do desenvolvimento infantil e da aprendizagem de capacidades necessárias à aprendizagem da leitura e escrita.

Para Soares (2001), as práticas em sala de aula devem estar orientadas de modo que se promova a alfabetização na perspectiva do letramento, proporcionando a construção de habilidades para o exercício efetivo e competente da tecnologia da escrita. Nesta perspectiva, as orientações teórico-metodológicas em estudo, foram classificadas em três grupos, quais sejam: o papel da literatura no desenvolvimento infantil; a transição da educação infantil para o ensino fundamental de 9 anos; e o currículo.

\section{O papel da literatura no desenvolvimento infantil}

Três artigos que compõem a seção Caleidoscópio, todos da edição 38 da Revista Criança, destacam o papel da literatura no processo de desenvolvimento infantil e para aprendizagem de conceitos geográficos. Destacamos estes artigos por reconhecermos que o contato com a literatura infantil promove o letramento das crianças, estimulando as habilidades de leitura e escrita, aprender a ler e escrever.

No artigo $O$ papel dos contos de fadas na construção do imaginário infantil, Vieira (2005) afirma que discursos que proclamam a importância da literatura tornaramse recorrentes entre os profissionais da área da educação. Atualmente não há quem discuta a atuação decisiva da literatura infantil na formação e no desenvolvimento do psiquismo humano, apesar de, alguns estudiosos, acreditaram que a narrativa dos contos de fadas provoca sofrimentos e angústias, repercutindo negativamente na vida futura das crianças, gerando medos e inseguranças. Porém, ela afirma estar ao lado daqueles que defende os contos de fadas:

Estamos do lado daqueles que são a favor dos contos de fadas, que acreditam no valor e na verdade que se revelam nessas histórias arcaicas, na força e na coragem que podem surgir, exatamente, pelo impacto do encontro direto com a fraqueza, o desamparo, o medo, a necessidade de luta para alcançarmos nossos objetivos (VIEIRA, 2005, p. 8).

Educação e Fronteiras On-Line, Dourados/MS, v.9, n.26 p.154-165, maio/ago. 2019. 
Para a autora, a ficção sistematiza fatos e verdades que não podem ser expressos pela razão, nem identificados pela lógica. Além disso, propõe Vieira (2005), os contos de fadas atuam no desenvolvimento intelectual e emocional das crianças, e, por isso, deveriam ser um foco de trabalho frequente nas escolas. Isso implicaria no fato de que os professores assumissem uma postura de desenvolvimento pessoal com seu próprio inconsciente, favorecendo o encontro das crianças com seu mundo interno.

Vieira (2005) defende a ideia de que os contos de fadas são narrativas simbólicas, extremamente simples, primitivas, capazes de transmitir experiências subjetivas e complexas as crianças. Assim, este gênero textual permite que os educandos desenvolvam habilidades como, por exemplo, a autoconfiança. Além disso, na visão da autora, os contos de fada apresentam sempre uma estrutura e uma temática: falam da busca da totalidade psíquica e da plenitude do ser.

Os argumentos de Coelho (2005) no artigo $O$ conto de fadas caminham na mesma direção ao afirmar que o fato dos contos de fadas ainda encantarem tantas pessoas se dá porque eles se caracterizam como lições de vida: "por mais que os homens transformem o mundo em que vivem com sua inteligência e trabalho, sua natureza humana não muda" (COELHO, 2005, p. 10). Para a autora isso ocorre porque a matéria-prima dos contos de fada é extraída das verdades humanas e, portanto, não envelhece.

Neste sentido, é papel do professor incluir em seu planejamento práticas que envolvam esse gênero textual. Marandola e Marandola Júnior (2005), no artigo Conversando e contando histórias, recriando lugares, relatam como isso foi feito, articulando conhecimentos da área de Geografia à literatura, em uma escola municipal de Londrina/PR. Este trabalho foi realizado por acreditarem que as histórias infantis podem significar para as crianças pequenas a fusão de dois mundos, o da fantasia, e o do real. Está é, segundo os autores, uma das grandes virtudes da literatura para o ensino e o aprendizado de conhecimentos geográficos.

A prática descrita pelos autores, vivenciada por uma professora da mencionada escola, caracterizava-se pela narração de uma história, no caso, o clássico Patinho Feio, por meio da qual foi realizada a exploração das gravuras que compunham o livro e conversas com as crianças sobre o enredo da história, aproximando os lugares e situações descritas com os lugares e situações vivenciadas por elas. Os espaços que o patinho passou durante a narrativa foram comparados com aqueles do cotidiano das crianças, como as suas casas, a sala de aula, o refeitório. O registro desse trabalho foi feito pelas crianças por meio de desenhos. Assim, a professora conseguiu ter uma visão mais ampla de como as crianças haviam compreendido tais comparações. Nesta perspectiva, Marandola e Marandola Júnior (2005) afirmam que a recriação de lugares por meio da literatura e de desenhos é uma forma de exercitar várias utopias que a educação contemporânea tem buscado alcançar, colocando em relevo as experiências das crianças e estimulando a criticidade, a criatividade, a autonomia e o autoconhecimento.

\section{Transição da educação infantil para o ensino fundamental}

Em função da ampliação do ensino fundamental, as crianças com idade entre cinco e seis anos estão transitando da educação infantil para este nível de ensino, onde, 
tradicionalmente, há uma preocupação maior com o processo de apropriação da linguagem escrita. Por isso, destacamos nesta análise três artigos que tratam dessa temática, os quais compõem a seção Caleidoscópio da edição 42 da Revista Criança.

Segundo Lopes e Mendes (2006), no artigo Desafios de um novo tempo, a inclusão das crianças com seis anos de idade no ensino fundamental ampliado coloca novos e grandes desafios para a área da educação, enfatizando que antes de tudo esta é uma questão que deve ser, prioritariamente, tratada no campo do direito das crianças a uma educação que promova a sua formação humana. As autoras explicam que esse processo só beneficia os alunos se for realizado pensando nas especificidades da idade, garantindo a implementação deste atendimento e promovendo a melhoria do trabalho pedagógico voltado a faixa etária em destaque.

Nesse sentido, devem ser elaboradas diretrizes, metas e objetivos, em consonância com a legislação vigente e com os documentos oficiais orientadores, afirmam Lopes e Mendes (2006). Elas dizem que é preciso esclarecer que a inclusão da criança de seis anos no ensino fundamental não significa antecipar o modelo educacional que ora se coloca para este nível de ensino:

É necessário considerar quem é esta criança, quais são as suas formas de aprender, como se dá sua inserção na cultura, a importância das interações para o seu desenvolvimento e aprendizagem e, sobretudo, o valor do brincar como forma primordial da criança ser e de estar no mundo (LOPES; MENDES, 2006, p. 8).

Além disso, são necessárias algumas mudanças, dentre elas estão à organização do espaço físico e a elaboração de materiais flexíveis e desafiadores. Pagel e Nascimento (2006), em A criança de 6 anos no ensino obrigatório: um avanço social, consideram que, apesar dos desafios de incluir a criança de seis anos no ensino fundamental, esta é uma ação democratizante da educação pública brasileira.

No artigo A criança de 6 anos no ensino fundamental, Lima (2006) considera a inclusão das crianças com seis anos neste nível de ensino uma ação importante, pois corresponde a uma necessidade da organização contemporânea da vida urbana, e neste sentido o Brasil chegou tardiamente à essa obrigatoriedade. A autora diz ainda que "a maior parte dos argumentos a favor e contra esta inclusão discute a questão a partir da perspectiva das aprendizagens escolares e do desenvolvimento da criança centralizados na capacidade cognitiva" (LIMA, 2006, p. 12).

Para garantir a qualidade desta transição, Lima (2006) defende a realização de mudanças no currículo para que as práticas culturais da infância ganhem espaço no ensino fundamental. Sugere que "atividades que envolvam música e movimento sejam equiparadas em importância às atividades mais especificamente voltadas a apropriação da leitura e da escrita. Busca-se, assim, uma escolarização que vise à formação da criança enquanto ser cultural em desenvolvimento" (LIMA, 2006, p. 12).

A forma da criança de seis anos aprender também é diferente, pois, segundo Lima (2006), a memória infantil nesse período está muito ligada a percepção. Portanto, as ações pedagógicas precisam estar adequadas a esta condição. Outro aspecto evidenciado pela autora é o fato de que como este é um período onde as crianças estão desenvolvendo a imaginação é importante que os professores incluam em seus 
planejamentos atividades que envolvam o lúdico. Apesar da necessária reestruturação do currículo e de verificarmos a importância de haver uma readequação das atividades para a nova faixa etária do ensino fundamental, não podemos deixar de lado o processo de apropriação da leitura e da escrita. Afinal, estas são atividades fundamentais para o desenvolvimento e humanização das crianças, relativiza Lima (2006).

Segundo Lima (2006), escrever e ler são tarefas distintas relacionadas entre si, mas com especificidades. Para autora o no processo de desenvolvimento, a criança realiza várias aquisições que estão relacionadas à apropriação da leitura e da escrita, mas que, na verdade, antecedem o ato de escrever no papel propriamente dito. O que ocorre é que muitas destas aquisições são da alçada da educação infantil e, também, da vivência escolar aos seis anos.

\section{Currículo}

$\mathrm{O}$ que ensinar às crianças na educação infantil? $\mathrm{O}$ que priorizar em um currículo para a educação infantil? Respostas a essas questões podem ser encontradas nos artigos que compõem a seção Caleidoscópio da edição 43 da Revista Criança.

Segundo Coutinho e Rocha (2007), em Bases curriculares para a educação infantil? Ou isto ou aquilo, definir criticamente bases curriculares para a educação infantil exige redefinir, em uma perspectiva social, histórica e cultural, a constituição da criança, da infância e do conhecimento. Para as autoras, um currículo correto para educação infantil é aquele que permite que a construção dos conteúdos sistematizados para as crianças seja realizada por meio de suas relações com mundo. Para Filho (2007), conteúdo é tudo aquilo o que medeia a relação professor/aluno, e conteúdo correto é aquele que faz sentido na vida de cada um deles.

Nascimento (2007) nos orienta que para definir quais são os melhores assuntos a serem trabalhados é necessário conhecer as crianças, já que uma turma nunca é igual à outra. Para a autora, a definição dos conteúdos que serão sistematizados por meio do currículo é uma tarefa complexa. Uma forma de fazer isto, segundo a autora, é trabalhar por meio de projetos, pois estes exigem cooperação, interesse, curiosidade e pesquisa por parte de todos os envolvidos. Nesse sentido, destaca-se a experiência do município de São Luís (Maranhão) por ter um currículo que visa, principalmente, os processos de alfabetização e letramento.

O grande desafio, segundo Pedrosa e Abreu (2007), era constituir um currículo que levasse em conta a complexidade dos processos em discussão, sem descuidar dos outros campos de saberes que compõe a educação sistematizada. Assim, segundo as autoras em estudo, algumas mudanças foram feitas nas escolas da rede municipal de São Luís. Uma delas foi à criação de ambientes alfabetizadores, que se expressam tanto na organização da escola e das salas de aula, como na rotina e nas atividades didáticas. A criança tem que aprender a gostar de estar inserida no mundo das letras. Para as autoras, o desafio é garantir a todas as crianças e jovens o direito de aprender a ler, a escrever a usar nossa língua em diferentes contextos e situações.

Para Pedrosa e Abreu (2007), os educandos são colocados em contato com uma infinidade de textos, dos mais diversos gêneros textuais, para depois serem apresentados a situações de reflexão sobre a linguagem escrita: "esse ambiente alfabetizador tem propiciado, em processo crescente, a compreensão e a valorização da cultura escrita, a

Educação e Fronteiras On-Line, Dourados/MS, v.9, n.26 p.154-165, maio/ago. 2019. 
apropriação do sistema alfabético, o desenvolvimento da oralidade e da prática de leitura e de produção textual", afirma as autoras. As educadoras ainda contam que a forma adotada pelo município para garantir adequadamente os processos de ensinoaprendizagem sistematizados no currículo, foi por meio da realização de um diagnóstico sobre os conhecimentos que as crianças já possuíam a respeito da escrita, o que serviu para ajudar na seleção das atividades que garantam resultados satisfatórios.

Outra estratégia adotada pelo programa em discussão, a fim de garantir a efetivação das práticas educativas, segundo Pedrosa e Abreu (2007), foi à formação continuada dos profissionais, ações estas que se revelaram, principalmente em momentos de reflexão sobre a prática, em forma de conversas e discussões construtivas, afinal o professor também tem que ter uma relação prazerosa com a leitura e a escrita.

Em outra perspectiva, Borba (2007) defende a brincadeira como experiência no currículo da educação infantil. Segundo a autora, estudos históricos mostram que muitos jogos e brincadeiras antigos permanecem, ainda hoje, em muitas partes do mundo, definindo brincadeira como aquilo que identifica e diversifica os seres humanos em diferentes tempos e espaços, sendo uma ação que contribui para a construção da vida social coletiva. A autora alerta para compreensão de que crianças são sujeitos produtores de cultura, o que provocou, em algumas situações, revisão dos currículos para o nível de ensino em discussão: dimensões culturais como a brincadeira e as artes ganharam força e prioridade equiparada a atividades como leitura e escrita.

\section{CONCLUSÃO}

O desenvolvimento deste artigo passou por muitas etapas até chegar ao resultado que você leitor acabara de ler. A primeira delas foi a seleção dos exemplares da Revista Criança, o que possibilitou a organização e a coerência do estudo ora apresentado. Para sua consecução foram realizados, inicialmente, estudos sobre a relação entre alfabetização e letramento, definindo-os como processos diferentes, porém indissociáveis. Em seguida, realizou-se a leitura atenciosa da fonte da pesquisa Revista Criança - conhecendo suas seções, e sistematizando, os principais assuntos do impresso. Como resultado do processo selecionou-se a seção Caleidoscópio para ser mapeada, buscando as mais frequentes orientações teórico-metodológicas que envolvessem os processos de alfabetização e letramento. O critério de escolha foi norteado pela variedade de assuntos trazidos por essa seção, que propunha três pontos de vista sobre uma mesma temática. Assim elas foram divididas em tópicos, que foram agrupados por tipo de orientação, conforme apresentadas neste artigo: papel da literatura infantil; relação entre cuidar e educar; avaliação; transição da educação infantil para o ensino de nove anos; currículo.

As conclusões apontam para ocorrência de poucas orientações teóricometodológicas acerca dos processos de alfabetização e letramento para educação infantil na Revista Criança. Assim, subentende-se este ser um tema de pouca relevância para este nível de ensino, caracterizado principalmente pelo cuidar, no sentido de satisfazer as necessidades básicas humanas, onde as atividades educativas sistematizadas perdem sua prioridade. Para finalizar, verificamos que o mapeamento acerca das principais orientações teórico-metodológicas presentes na seção 
Caleidoscópio da Revista Criança permitiu-nos ampliar as possibilidades de investigação acerca desse importante impresso pedagógico.

\section{REFERÊNCIAS}

AMORIM, Adenice; BRITO, Mônica; BARROS, Siriene. Pare! Respeite-me, também sou cidadão! Revista Criança do Professor de Educação Infantil, Brasília, DF: MEC, n. 39, p. 15-17, abr. 2005.

ARAGÃO, Rosana. O portfólio como novo instrumento de avaliação. Revista Criança do Professor de Educação Infantil, Brasília, DF: MEC, n. 41, p. 14-17, nov. 2006.

BEAUCHAMP, Jeanete. Integração de creches e pré-escolas e habilitação de professores: qualidade na Educação Infantil. Revista Criança do Professor de Educação Infantil, Brasília, DF: MEC, n. 39, p. 10-11, abr. 2005.

BORBA, Angela. A brincadeira como experiência de cultura na educação infantil. Revista Criança do Professor de Educação Infantil, Brasília, DF: MEC, n. 44, p. 12-14, nov. 2007.

CAMARGO, Fátima. Criança e educação: uma trajetória cultural e institucional. Revista Criança do Professor de Educação Infantil, Brasília, DF: MEC, n. 39, p. 12-14, abr. 2005.

COELHO, Nelly. O Conto de Fadas. Revista Criança do Professor de Educação Infantil, Brasília, DF: MEC, n. 38, p. 10-12, jan. 2005.

COUTINHO, Angela; ROCHA, Eloisa. Bases curriculares para a educação infantil? Ou isto ou aquilo. Revista Criança do Professor de Educação Infantil, Brasília, DF: MEC, n. 43, p. 10-11, ago. 2007.

FERNANDES, Claudia. Avaliação sempre envolve uma concepção de mundo. In: BRASIL. Revista Criança do professor de educação infantil. MEC, nov. 2006, n. 41, p. 9-11.

FRADE, I.C.A.S. Revistas pedagógicas: qual é a identidade do impresso? s/d. In: GALVÃO, A.M.O; BATISTA, A. A.G (orgs). Leitura: práticas, impressos e letramento. Belo Horizonte: Autêntica, 2011.

GUEDES, Adriane. A comunicação com bebês e com crianças pequenas: A imitação como forma de conhecer o mundo. In: BRASIL. Revista Criança do professor de educação infantil. MEC, dez. 2006, n. 46, p. 10-13.

JUNQUEIRA FILHO, Gabriel de A. Os conteúdos em educação infantil. In: BRASIL. Revista Criança do professor de educação infantil. MEC, ago. 2007, n. 43, p. 12-13.

LIMA, Elvira. A criança de 6 anos no Ensino Fundamental.In: BRASIL. Revista Criança do professor de educação infantil. MEC, dez. 2006, n. 42, p. 12-15. 
LOPES, Karina; MENDES, Roseana. Desafios de um novo tempo. In: BRASIL. Revista Criança do professor de educação infantil. MEC, dez. 2006, n. 42, p. 8-9.

NASCIMENTO, Anelise. Currículo e práticas pedagógicas na educação infantil. In: BRASIL. Revista Criança do professor de educação infantil. MEC, ago. 2007, n. 43, p. 14-17.

OLIVEIRA, Wanessa Gorri. A imprensa pedagógica como fonte e objeto para uma escrita da história da educação: em destaque a Prática pedagógica sugerida ao professor de educação infantil pela Revista Criança (1996-2006). 2011. 198 f.

Dissertação (mestrado em Educação) - Universidade Estadual de Maringá, Maringá.

PAGEL, Sandra; NASCIMENTO, Aricélia. A criança de 6 anos no ensino Obrigatório: Um avanço social. In: BRASIL. Revista Criança do professor de educação infantil. MEC, dez. 2006, n. 42, p. 10-11.

PEDROSA, Eliane; ABREU, Rosa. Alfabetização e letramento: A experiência de São Luís. In: BRASIL. Revista Criança do professor de educação infantil. MEC, nov. 2007, n. 44 , p. $10-11$.

ROCHA, A.S.; BERNARDO, D. G. Pesquisa bibliográfica: entre conceitos e fazeres. In: TOLEDO, C. A. A.; GONZAGA, M. T. C. (org.). Metodologia e técnicas nas áreas de Ciências Humanas. Maringá: EDUEM, 2001. p. 101-119.

SOARES, Magda. Alfabetização e letramento. São Paulo: Contexto, 2010.

SOARES, Magda. Letramento e alfabetização: as muitas facetas. Letrar é mais que Alfabetizar. Jornal do Brasil. São Paulo, 2001.

VIEIRA, Isabel. O papel dos Contos de Fadas na Construção do Imaginário Infantil. In: BRASIL. Revista Criança do professor de educação infantil. MEC, jan. 2005, n. 38, p. 8-91.

Recebido em: 14/02/2019

Aprovado em: 11/04/2019 